\title{
Vigencia del Darwinismo
}

\section{Cogency of Darwinism}

\author{
ENRIQUE P. LESSA
} Laboratorio de Evolución, Facultad de Ciencias, Universidad de la República, Montevideo, Uruguay
E-mail: lessa@fcien.edu.uy

\section{RESUMEN}

En este ensayo se presenta una revisión histórica del significado y legado del darwinismo, con énfasis en el último siglo. La principal conclusión es que la visión darwiniana de la evolución, con las modificaciones requeridas para dar cuenta de los grandes desarrollos de la disciplina, se ha impuesto y mantiene vigencia en nuestros días. En particular, el papel del azar, la evolución como proceso de "descendencia con modificación" a lo largo de diversas ramas del árbol de la vida, el pensamiento poblacional, el gradualismo y la selección natural son los principales legados de la obra de Darwin. En el caso de la selección, entendida como proceso poblacional de naturaleza estocástica, se propone que la visión de su papel ha sufrido dos procesos de expansión a partir del énfasis de Darwin en la selección direccional positiva. Una primera ampliación se consolidó en la primera mitad del siglo XX con el reconocimiento del importante papel que cumple la selección purificadora, así como la selección positiva débil. Una segunda ampliación se debió al reconocimiento de la variación neutral y de la selección contra variantes ligeramente deletéreas. En suma, la teoría de la selección actual contempla todo el espectro de efectos posible de la variación genética sobre la eficacia darwiniana. En el contencioso campo de la macroevolución, tanto los procesos de especiación como las explicaciones de los patrones macroevolutivos han sido dominados de modo creciente por la microevolución, con un reconocimiento creciente del papel de la selección positiva. Sin embargo, la elaboración de una visión jerárquica de la individualidad biológica ha sido uno de los legados importantes de las últimas décadas. El "pensar en base a árboles", tan dominante en el evolucionismo actual, representa una realización moderna de la visión darwiniana de la evolución.

Palabras clave: Evolucionismo moderno, neodarwinismo, neutralismo, teoría de la selección, unidades de selección.

\begin{abstract}
This essay presents a review of the historical significance and legacy of Darwinism, with emphasis on the last 100 years. The main conclusion is that the Darwinian view of evolution has prevailed and maintains its validity, with the changes required to account for the substantial developments of the discipline. In particular, the role of chance, evolution as a process of "descent with modification" along many branches of the tree of life, populational thinking, gradualism, and natural selection constitute the main legacy of Darwin's work. In the case of selection, understood as a stochastic process, I propose that views about its role have suffered two processes of expansion from Darwin's emphasis on positive, directional selection. A first expansion took place during the first half of the 20th century, with the recognition of the important role played by purifying, as well as weak positive selection. A second expansion was due to the recognition of neutral variation and of selection against weakly deleterious variants. In sum, selection theory contemplates the entire spectrum of effects of genetic variation on Darwinian fitness. In the contentious field of macroevolution, both the processes of speciation and the explanations of macroevolutionary patterns have been increasingly dominated by microevolution, with a growing recognition of the role of positive selection. However, the development of a hierarchical view of biological individuality has been one of the important legacies of the last decades. "Tree thinking", so dominant in modern evolutionism, represents a modern realization of the Darwinian view of evolution.
\end{abstract}

KEYwORDS: Modern evolutionism, neodarwinism, neutralism, selection theory, units of selection.

Pp. 73-84 en D’Elía, G. 2009. Una celebración de los aniversarios darwinianos de 2009. Gayana 73 (suplemento): 1-88. 


\section{INTRODUCCIÓN}

En 2009 se cumplieron 200 años del nacimiento de Charles R. Darwin y de la publicación de la Filosofia zoológica, de Jean Baptiste de Lamarck, y 150 años de la publicación de El origen de las especies, el libro fundamental de Darwin, y uno de los pilares de la ciencia y la cultura modernas. Es, pues, un buen momento para examinar el significado de la transformación darwiniana de la biología y el estado actual de la teoría de la evolución. La tesis central de este ensayo es que la teoría evolutiva moderna es esencialmente darwinista, aunque incorpora los importantes desarrollos acaecidos desde 1859.

Aunque no me detendré a examinar en detalle la génesis y significación histórica de la obra de Darwin, creo conveniente mencionar algunos puntos generales. En primer lugar, comparto la visión de que, mientras que varios se adelantaron a Darwin al proponer visiones evolutivas, más o menos desarrolladas, de la diversidad biológica, la obra darwiniana es acertadamente vista como fundacional del evolucionismo moderno. El pensamiento evolucionista predarwiniano evidencia numerosas flaquezas que solamente fueron plenamente resueltas por Darwin. En particular, muchos pensadores anteriores especularon sobre la transformación de las especies, sin realmente proponer teorías evolutivas completas y coherentes. Darwin, en cambio, se planteó reunir toda la biología de su época en torno a su teoría, en un camino de ida y vuelta en el cual el conocimiento acumulado provee vasta evidencia sobre el fenómeno evolutivo $y$, a la vez, se ve iluminado por la teoría de la evolución. Por otra parte, muchas ideas evolucionistas predarwinianas describían a la evolución como un proceso más o menos lineal, desde lo primitivo y sencillo hacia lo avanzado y complejo. La noción de "progreso", epitomizada por la teoría de Lamarck de la tendencia inherente de la vida hacia la perfección, era central a buena parte del pensamiento predarwiniano, mientras que Darwin desestimó ese tipo de especulaciones para sustituirlo por un proceso mucho menos ordenado (de hecho, sin orden prefijado alguno), y desprovisto por cierto de cualquier significación finalista. En línea con buena parte de la historiografía sobre el tema (e.g., Cohen 1985; Mayr 1991), he suscrito la tesis de que el finalismo de corte vitalista era el núcleo de la visión lamarckista de la evolución, y que dicha visión tenía connotaciones extracientíficas que era necesario remover (Lessa 1996). Mientras que Lamarck se diferenció en buena medida de sus predecesores por ser el primero en proponer una teoría completa y coherente de la evolución, dicha teoría debió, a la larga, ser desechada fundamentalmente por sus connotaciones extracientíficas (y, cierto es también, por el mecanismo de herencia de los caracteres adquiridos que, o es completamente errado, o tiene posibilidades muy limitadas de operar en circunstancias muy particulares; véase Foster 2000).

Recordemos que Darwin fue uno de los primeros y más exitosos cultores de la geología actualista (los principios y procesos observables en la actualidad son suficientes para dar cuenta de la historia del planeta) y gradualista (la evolución geológica es lenta y gradual) de Lyell (1830), como lo ilustra su monografía sobre la geología sudamericana. Darwin hizo uso de la visión de Lyell de un planeta Tierra con una gran antigüedad, lo cual es imprescindible para permitir una evolución biológica que debía haber insumido muchos millones de años. Pero la adopción darwiniana del paradigma de la nueva geología fue mucho más allá de dicho campo. En efecto, el evolucionismo darwinista es, en cierto sentido, una adaptación del actualismo y del gradualismo a la realidad biológica. La adhesión de Darwin al actualismo explica, en parte, por qué no consideró completa su visión de la evolución hasta no haber encontrado un mecanismo, de entre los que operan también en el presente (la selección natural), capaz, en su visión, de dar cuenta de la historia evolutiva.

\section{LA EVOLUCIÓN SEGÚN DARWIN}

El evolucionismo de Darwin tiene como elementos esenciales su carácter gradualista, su descripción de la evolución como un proceso de diversificación a partir de ancestros comunes y a lo largo de diversas líneas de descendencia, y el proceso de selección natural operando, generación a generación, en las poblaciones, sin referencia adicional alguna. Por ejemplo, si una característica resulta favorable entre los miembros de una población, se propagará aún en el caso en que lleve, más adelante, a la extinción de la especie. Por otra parte, la selección puede favorecer la complejidad o la simplicidad, y más 
en general carece de una dirección prefijada que pueda asimilarse al "progreso", ni que decir a la "perfección".

Aceptar la evolución darwiniana implica, por tanto, bastante más que aceptar que la diversidad biológica no fue formada tal y como la conocemos por un creador; también implica que la misma es el producto de un proceso de ramificación y diversificación. Esta teoría reúne características que, en algunos casos en sí mismas y en otros por su amalgamamiento con las restantes, contribuyeron a una verdadera revolución científica:

1. Ruptura con el esencialismo. Darwin estableció una conexión entre la variación dentro de las especies y la divergencia entre ellas. Para ello debió romper la visión esencialista según la cual cada especie es inmutable y refleja su diseño por parte del creador, y la variación individual representa "ruido" que debe ser descartado para reconocer la esencia de cada especie.

2. Restricción a causas naturales. En contraste con muchas teorías y especulaciones precedentes, la evolución darwinista no invoca procesos ni factores de ordenamiento externos al mundo natural. No hay referencias a una orientación general hacia la perfección, ni una visión en la cual el proceso evolutivo adquiere un sentido más trascendente (por ejemplo, por su orientación hacia la aparición de una especie superior: la nuestra). En particular, el proceso de la selección natural, identificado por Darwin como el principal agente de cambio evolutivo, carece de propósito ulterior.

3. Unidad y diversidad de la vida. La unidad de la vida representa el legado de la herencia de una generación a la siguiente $y$, por esa vía, desde el ancestro común de los seres vivos a todos sus descendientes. A su vez, la "descendencia" que da continuidad y unidad a la vida, ocurre "con modificación", generando al mismo tiempo diversidad. Vemos entonces que la vida, y por ende la biología, evidencian a la vez importantes elementos en común y una heterogeneidad abrumadora. En la época de Darwin, la unidad y diversidad de la vida se manifestaban en la clasificación biológica, en la anatomía, la fisiología, y el comportamiento, en la distribución espacial y temporal de la diversidad. 150 años después de la publicación de "El origen de las especies", conocemos aspectos de la organización biológica que eran sencillamente inimaginables en aquella época. Así, por ejemplo, encontramos evidencia de la unidad de la vida en el llamado código genético "universal". Su descubrimiento y la proclamación de que el código era el mismo "desde la bacteria (E. coli) hasta el elefante" constituyó una significativa constatación de aquella unidad vislumbrada por Darwin. Pero hoy conocemos unos 17 códigos genéticos alternativos, incluyendo, por ejemplo, nuestro propio código genético mitocondrial, diferente del de nuestro genoma nuclear. Se manifiesta, entonces, la diversidad de la vida en este nivel, al igual que en otros. Pero es también evidente que todos los códigos genéticos conocidos son variantes (de hecho, relativamente menores) de un único código ancestral. Este pequeño camino de ida y vuelta entre unidad y diversidad puede recorrerse en casi cualquier aspecto de la biología. La perspectiva darwiniana lleva a preguntas como las que siguen. ¿Podemos reconstruir la evolución de estas características? ¿Qué papel jugó la selección en el proceso de diversificación observado? ¿Qué papel jugaron otros procesos y factores, como el azar y las restricciones que acompañan a cualquier estructura compleja? El contexto natural para plantearse dichas preguntas es el del árbol de la vida, ya que los códigos genéticos son a la vez actores y productos del proceso darwiniano de descendencia con modificación a lo largo de las diversas ramas de la diversidad biológica.

4. Pensamiento poblacional. La selección natural, tal y como la concibieron Darwin y Wallace, es un proceso poblacional de carácter probabilístico. En su génesis, combina: 1) observaciones sobre la variación del mundo biológico en la naturaleza, tanto dentro como entre especies, 2) razonamientos inspirados en Malthus sobre las interacciones entre las acciones individuales y colectivas (particularmente en lo referente a la reproducción y al uso de los recursos) y la dinámica demográfica de las poblaciones, y 3) el conocimiento acumulado en la práctica de la selección artificial. Un proceso de esta naturaleza implica varios tipos de interacción, 
con frecuencia complejos y cambiantes, entre el genotipo y el fenotipo, y entre éste y la eficacia darwiniana. Comprender la evolución de una característica cualquiera implica no solamente identificar el origen de una variante, sino también interpretar el proceso que llevó a su persistencia y, si correspondiese, fijación en un linaje. Desde el origen (para mencionar un caso simple: una mutación) hasta la fijación de una variante, la misma ingresa en el juego darwiniano en el que el azar y la selección interactúan operando sobre ella. Aún es frecuente el error de pensar que la identificación del origen de una característica es suficiente (nadie duda que es necesaria) para dar cuenta de ella.

\section{LA OBRA DE DARWIN}

"El Origen de las Especies" es reconocido acertadamente como la obra fundamental de Darwin. Pero los aportes de su autor a la teoría evolutiva residen también en un conjunto de trabajos adicionales, cuya significación no fue siempre reconocida. Debemos a Michael Ghiselin (1969) un estudio completo de las publicaciones de Darwin y el reconocimiento de que cada una de ellas representa el análisis detallado de un aspecto significativo de su teoría. Así, el hecho de que Darwin dedicase varios años a la preparación de una monografía sobre la diversidad y taxonomía de un grupo particularmente especializado de crustáceos antes de la publicación de "El origen" no fue, para Ghiselin, una desviación de su atención hacia problemas triviales, sino un ejercicio pleno de la idea de que aún los grupos en apariencia más especializados contienen evidencias de sus relaciones de parentesco internas y con el grupo en el cual se enclavan, y de muchas de las etapas de su evolución. Esa capacidad de reconocer conexiones genealógicas es un aspecto clave de la visión darwiniana de la evolución, y encuentra algunos de sus mayores desafíos en el estudio de grupos muy especializados. Convergen aquí dos problemas de importancia: la reconstrucción filogenética y la posibilidad de descomponer empíricamente lo que parecería ser un salto de grandes dimensiones de un grupo a otro en una serie de pasos de menor magnitud. Un segundo ejemplo de importancia en el análisis de casos particulares, se encuentra en la monografía que Darwin dedicó al origen de nuestra especie, publicada en asociación con otra sobre la expresión de las emociones en los animales y los humanos. Darwin fue un pionero en el análisis comparativo y evolutivo del comportamiento animal y, al mismo tiempo, resolvió abordar de manera frontal la ubicación de nuestra especie en el árbol de la vida, las líneas de evidencia (anatómica y etológica, entre otras) que develan dicha ubicación, y el desarrollo de un escenario posible para la evolución de nuestra estirpe. Aunque pudo haber sido de otra manera, Darwin acertó en algunas de las grandes cuestiones relativas a nuestro lugar en el árbol de la vida como son: nuestro parentesco preferencial con chimpancés y gorilas, el origen africano de los homínidos, y el hecho de que la evolución de la postura erecta y la locomoción bípeda precedió, y seguramente permitió, el desarrollo de la capacidad de construir herramientas de creciente sofisticación y su asociación con el aumento del tamaño y capacidades del cerebro. $\mathrm{Si}$ bien la recolección de fósiles de homínidos tiene sus bases en el siglo XIX, hoy contamos con un registro que cubre ampliamente los últimos 5 a 7 millones de años y podemos acceder a evidencias genéticas y genómicas que nos permiten examinar las hipótesis darwinianas con herramientas inimaginables hace 150 años.

Otras dos monografías de Darwin merecen ser destacadas porque contienen importantes extensiones teóricas (aunque, en línea con el estilo de su autor, incluyen una amplia y cuidadosa documentación de observaciones del mundo natural) a la teoría de la evolución. En primer lugar, en su trabajo sobre selección sexual Darwin reconoció que muchas características de los seres vivos no pueden considerarse adaptaciones "al ambiente", sino que están más bien asociadas a la reproducción. Entre ellas se cuentan numerosos comportamientos y estructuras asociadas al cortejo, la cópula y el cuidado parental en los animales, otras ligadas a la polinización en las plantas, etc. Darwin identificó el proceso de selección sexual como un caso particular de selección natural asociado a estos fenómenos. Sus ideas se mantuvieron casi como una nota al pie de su gran teoría de la evolución hasta mediados del siglo XX, periodo en el que fueron retomadas con vigor para constituir la base del moderno estudio del comportamiento y las estrategias reproductivas de los organismos. En segundo lugar, su trabajo sobre las interacciones entre plantas e insectos polinizadores puso en evidencia el fenómeno de 
la coevolución, en los que la selección operando dentro de cada una de las especies en interacción resulta en un fenómeno de evolución concertada. Allí se encuentra uno de los gérmenes de la moderna ecología evolutiva.

\section{MUTACIONISMO Y TEORÍA SINTÉTICA}

En las primeras décadas del siglo XX, el campo de la evolución estaba bastante dividido. Aunque las ideas de Darwin sobre la evolución como proceso de diversificación a partir de ancestros comunes estaban ampliamente aceptadas, las divergencias sobre los mecanismos y procesos de la evolución eran importantes. Por una parte, una pequeña fracción de los naturalistas había aceptado a la selección natural como el mecanismo principal (o aún como un mecanismo importante) de la evolución. Con excepciones (principalmente en Inglaterra), los naturalistas adherían al concepto de herencia de los caracteres adquiridos de Lamarck, algunas veces en términos estrictamente científicos, y en otras ocasiones con connotaciones vitalistas. Algo más avanzado el siglo, se consolidó en la Unión Soviética un neolamarckismo peculiar, centrado en la herencia de los caracteres adquiridos, como la doctrina oficial y la única compatible con el marxismo.

Por otra parte, el redescubrimiento de las leyes de Mendel a comienzos del siglo XX generó, en primera instancia, un movimiento según el cual la mutación, y no la selección, guiaba el proceso evolutivo. Sin embargo, entre los genetistas surgieron figuras como Ronald Fisher, Sewall Wright y John Haldane, que reconocieron a la mutación como el primer paso de génesis de variación genética, cuyo destino era definido, en el juego poblacional, por la selección natural. Estos y otros autores desarrollaron modelos matemáticos de evolución por selección, operando sobre la variación genética.

La difícil convergencia del naturalismo y la genética evolutiva tuvo lugar gracias al trabajo pionero de Theodosius Dobzhansky, cuya obra "La genética y el origen de las especies" (1937) procura, precisamente, reunir la nueva disciplina de la genética con la obra darwiniana. En fuerte interacción con Dobzhansky, Ernst Mayr publicó su monumental "La sistemática y el origen de las especies" (1942), incorporando más fuertemente al naturalismo y el estudio de la biodiversidad en el marco de una "teoría sintética" o "neodarwinista" de la evolución. De particular relevancia en las obras de Dobzhansky y Mayr son el concepto biológico de especie y un estudio detallado de los procesos de formación de especies. La especiación, como se la conoce desde entonces, es por lo general un fenómeno poblacional y gradual como proceso, pero resulta en la formación de unidades discretas, las especies, que ingresan al juego macroevolutivo.

La teoría neodarwinista se consolidó al promediar el siglo XX y, a pesar de las enormes transformaciones de la biología desde entonces y de los no pocos desafíos y críticas a los que ha sido sometida, sigue siendo la visión dominante de la evolución hasta nuestros días. Sus componentes esenciales son:

1. Herencia mendeliana. La incorporación de la genética moderna al darwinismo permitió, por una parte, el rechazo definitivo del lamarckismo $y$, por otra, resolver la evidente dificultad de cualquier teoría evolutiva que no partiese de un conocimiento positivo de los mecanismos de la herencia.

2. Resolución del aparente antagonismo entre la naturaleza discreta de la variación genética y el carácter continuo de buena parte de la evolución gradual. Fisher y otros establecieron los fundamentos de la genética cuantitativa en parte para resolver este punto.

3. Carácter aleatorio de la mutación. La teoría sintética adoptó la noción de que las mutaciones no representaban, en sí mismas, respuestas adaptativas a desafíos ambientales, sino que ocurrían por diversas causas que nada tenían que ver con la adaptación. Gradualmente se han ido reconociendo como agentes mutagénicos diversos agentes fisicoquímicos, tanto externos (e.g., radiación) como resultantes de la actividad biológica (e.g., radicales libres). Más recientemente se ha tomado conciencia de que la propia maquinaria de replicación y reparación del ADN es imperfecta e introduce o tolera mutaciones con frecuencias bajas pero consistentes. En suma, se entiende que las mutaciones resultan de procesos perfectamente estudiables, pero pueden considerarse como aleatorias con respecto a su valor adaptativo. 
4. Formulación matemática de algunos procesos evolutivos fundamentales. Fisher, Wright y Haldane fueron pioneros en expresar la teoría del cambio evolutivo en términos de variaciones en las frecuencias alélicas en las poblaciones. Los alelos tienen un destino expresable en modelos matemáticos que incorporan, no solamente su origen mutacional, sino los cambios en su frecuencia resultantes de procesos tales como la selección natural (a favor o en contra de alelos y sus combinaciones genotípicas) y la migración. Curiosamente, Fisher y Wright consideraron, y en cierta medida desarrollaron, modelos de evolución sin selección, definidos esencialmente por la mutación y la deriva genética. Sin embargo, la teoría sintética o neodarwinista mantuvo un perfil esencialmente seleccionista.

5. Concepto biológico de especie y proceso de especiación. Dobzhansky y Mayr fueron responsables de la adopción, luego generalizada, del neodarwinismo emergente por parte de los naturalistas. Para ello desarrollaron y aplicaron los modelos de Fisher, Wright y Haldane a la diversidad biológica, pero además definieron con claridad problemas propios del naturalismo. Una definición clara de la especie biológica como unidad esencial de la diversidad, y una visión de los procesos de formación de especies (especiación) y de los mecanismos que las mantienen como entidades discretas (mecanismos de aislamiento), fueron contribuciones fundamentales a la consolidación de la teoría sintética.

6. El registro fósil. George Gaylord Simpson contribuyó fuertemente a consolidar la noción de que el registro fósil permitía, por una parte, desechar la visión de progreso lineal impulsada por el vitalismo y, por otra, adoptar la visión darwinista de evolución sin orden predefinido, lenta, gradual, y posiblemente guiada por la selección natural a lo largo de diversas ramas del árbol de la vida.

\section{LOS ÚLTIMOS CINCUENTAAÑOS: DESAFÍOS Y DESARROLLOS}

En 1959, a 100 años de la publicación de "El origen de las especies", la teoría sintética de corte neodarwinista estaba plenamente consolidada y cómodamente dominaba el pensamiento biológico. Diez años más tarde, sin embargo, la situación parecía ser muy diferente, ya que habían surgido con fuerza al menos dos teorías que desafiaban de manera frontal algunos de los principales puntos de vista de la teoría sintética. Por otro lado, surgieron o se consolidaron también otros desarrollos que, de manera más indirecta, plantearon importantes desafíos a la visión imperante.

\section{La Teoría Neutral de Evolución Molecular}

El neodarwinismo reconocía, en función de su impacto fenotípico y adaptativo, dos grandes clases de mutaciones. Por una parte, la mayoría de las mutaciones serían deletéreas, y enfrentarían por tanto la acción de la selección purificadora, también llamada negativa. Por otra parte, se entendía que ocasionalmente ocurrían mutaciones favorables (en sí mismas o en combinación con otras), que constituían la base de la evolución adaptativa, al influjo de la selección positiva. Debemos recordar que, al promediar el siglo XX, la amplia mayoría de las mutaciones pasibles de ser estudiadas eran reconocidas por sus efectos fenotípicos.

Al promediar la década de 1960 se había acumulado un pequeño número de secuencias de proteínas de diferentes especies. Para sorpresa de los evolucionistas, las especies parecían acumular diferencias aminoacídicas a una tasa aparentemente uniforme y característica de cada proteína. La noción de un "reloj molecular" surgió como una interpretación de ese patrón inesperado. Pero esa caracterización de la evolución molecular no condecía con la visión que tenía el neodarwinismo de la evolución. Ciertamente, la evolución morfológica, estudiada desde hacía más tiempo, es normalmente errática en su ritmo, como lo evidenciaba el registro fósil. Por otra parte, se entendía que la selección positiva dependía de la aparición fortuita de cambios favorables a intervalos seguramente irregulares. Simplificando algo las cosas, podemos decir que el reloj molecular, constatado empíricamente, constituía un patrón emergente sin una explicación a la vista.

E1 segundo desarrollo relevante tuvo lugar a partir de 1966, año en el cual se publicaron los primeros estudios sistemáticos de variación 
alélica, en humanos y en Drosophila, en base a la electroforesis. Los polimorfismos detectados por esta vía resultaron ser mucho más abundantes que lo esperado. En este caso, y en primera instancia, existían dos visiones de cómo podría ser la variación alélica en el marco del neodarwinismo. Algunos genetistas suponían que la selección direccional debía ser la forma más común de selección positiva, y esperaban por tanto que la mayoría de los loci fuesen monomórficos (o contuviesen, en todo caso, un alelo silvestre favorable y variantes raras, seguramente deletéreas, a bajas frecuencias). Otros, notoriamente Dobzhansky, suponían que la selección podría favorecer polimorfismos balanceados, en base a ventajas que podrían tener los individuos heterocigotas por sobre los homocigotas. En primera instancia, por tanto, la amplia variación evidenciada por electroforesis de proteínas parecía dar la razón a Dobzhansky, permitiendo la asimilación de los nuevos datos a la teoría sintética.

En una serie de trabajos fundamentales (particularmente Kimura \& Ohta 1971), Motoo Kimura propuso una teoría alternativa para dar cuenta, en un mismo marco conceptual, del reloj molecular emergente de los estudios de secuencias proteicas y de los abundantes polimorfismos descubiertos mediante electroforesis de proteínas. En efecto, la teoría neutral predice, simultáneamente, la existencia y persistencia de polimorfismos involucrando alelos estrictamente equivalentes en relación a su valor adaptativo (i.e., neutros), y la acumulación de sustituciones (diferencias fijas entre especies) a un ritmo estadísticamente constante. Pasados los primeros momentos de desarrollo de sus ideas, Kimura llegó a las siguientes conclusiones:

a) La mayoría de las mutaciones que afectaban las cadenas aminoacídicas eran deletéreas, en consonancia con la visión clásica.

b) Una pequeña fracción estaba formada por mutaciones favorables y, también en línea con la visión clásica, constituían la base de la evolución adaptativa.

c) Pero existía una nueva clase de mutaciones, aquéllas estrictamente neutras. Descontando las mutaciones deletéreas, que no podían persistir más que a frecuencias muy bajas (en particular si eran recesivas), las mutaciones neutras eran mucho más numerosas que las favorables. De hecho, Kimura sostuvo que la mayor parte de la variación intraespecífica, así como la mayoría de las sustituciones evolutivas, eran atribuibles a las mutaciones neutrales.

No detallaremos aquí el modelo neutral (disponible, por otra parte, en casi cualquier libro de texto de genética de poblaciones o evolución). En cambio, señalaremos que la teoría neutral es la hipótesis nula necesaria para realizar predicciones y someterla a pruebas empíricas. En términos muy generales, algunas predicciones de la teoría neutral han pasado a ser parte de lo esperado en los análisis moleculares. En particular, la mayoría de los genes evoluciona a tasas relativamente regulares, y buena parte de los polimorfismos poblacionales incluyen variación aparentemente neutra. Sin embargo, en ambos casos es posible evidenciar apartamientos, por lo general sutiles, pero consistentes, de las expectativas de la teoría neutral. Los modelos cuasi neutrales (Ohta 1973) o aquellos que combinan el neutralismo con episodios de selección, se ajustan más que el neutralismo estricto para dar cuenta de la variación y evolución a nivel molecular. Sin embargo, el evolucionismo molecular actual retiene enormes componentes de la teoría neutral. Más que clasificar a priori a las mutaciones en categorías discretas (deletéreas, neutras, o adaptativas), hoy entendemos que la selección opera en un continuo, desde el extremo de las mutaciones fuertemente sometidas a selección purificadora hasta aquel de los ocasionales cambios fuertemente favorables, pasando por la región de cuasi neutralidad, dentro de la cual la neutralidad estricta es una posibilidad particular. En suma, la teoría neutral de la evolución molecular es el principal desarrollo conceptual desde la formulación de la teoría sintética, y ésta ha sido capaz, aunque no sin resistencias, de asimilar, adaptar y modificar sus principales contribuciones a una visión general de una selección natural variable en sentido e intensidad.

En cierto modo, la visión darwinista de una selección positiva, necesaria para dar cuenta de la adaptación biológica, implicaba la posibilidad de que la selección fuese a veces negativa. Esta posibilidad fue asimilada en la primera mitad del siglo XX, al conocerse el fenómeno mutacional de manera más directa. Postular que la mayoría de las 
mutaciones eran deletéreas significó explicitar una opción implícita en el concepto original de Darwin. En la segunda mitad del siglo XX llegó la hora de la explicitación y asimilación de la variación neutral, también implícita como posibilidad en la definición de selección.

Por otra parte, cabe recordar que el mecanismo darwiniano de la selección natural indica que ésta opera sobre los organismos, y es solamente a través de los componentes heredables de la variación individual que puede afectar el devenir de los genes. La acción de la selección natural positiva a nivel génico es fácil de entender si las diferencias adaptativas entre los genotipos son importantes. Pero ésta no es necesariamente ni la forma más eficiente ni la más común de selección. En poblaciones grandes, la selección débil, aún al punto de ser prácticamente indetectable, puede ser eficaz. Por otra parte, la selección puede operar fuertemente sobre un carácter fenotípico (como el tamaño corporal, por ejemplo), pero si éste tiene una base poligénica (distribuida entre numerosos genes), el efecto directo de la selección sobre cada uno de los genes puede ser extremadamente débil. Los dos argumentos no son nuevos, y fueron planteados con toda claridad por Fisher (1930).

Tal vez sea esperable, después de todo, que muchos estudios gen a gen encuentren dificultades para detectar la acción de la selección positiva, mientras que estudios multigénicos o genómicos encuentran, por acumulación, evidencias más claras de selección débil, pero consistente ( $\mathrm{Lu} \& \mathrm{Wu} 2005$ ).

\section{El Modelo de Equilibrios Puntuados}

Si el neutralismo desafió al neodarwinismo desde el nivel molecular, el modelo de equilibrios puntuados (Eldredge \& Gould 1972) lo hizo desde el registro fósil y los patrones macroevolutivos. Brevemente, el modelo plantea que las especies permanecen incambiadas morfológicamente durante millones de años (estasis) y solamente cambian, y lo hacen de manera brusca (puntuación) en asociación con la especiación. La turbulencia generada por el modelo tiene diversas vertientes que conviene separar. Por una parte, se encuentra la aparente brusquedad de la especiación y la asociación del cambio morfológico a la misma. Por otra parte, encontramos el fenómeno de estasis, del que cabe preguntarse sobre su frecuencia y sus causas. Finalmente, pueden analizarse las presuntas consecuencias o corolarios del modelo, en particular la proclamada ineficacia o intrascendencia de la selección clásica (a nivel organísmico) y el papel privilegiado de la selección de especies:

1. Especiación rápida y cambio morfológico. Actualmente existe relativo consenso en que el fenómeno de puntuación no ofrece mayores dificultades para el neodarwinismo. Para comenzar, Eldredge y Gould utilizaron el modelo de especiación peripátrida de Mayr para dar cuenta de la velocidad de la especiación, remitiendo por tanto a un proceso clásico y ampliamente aceptado por la teoría sintética. Por otra parte, existe hoy importante evidencia indicando que la especiación como proceso cae mucho más cómodamente en el marco del neodarwinismo de lo que el propio Mayr hubiese podido anticipar. Así, hoy reconocemos que la selección natural, más que la divergencia al azar, cumple un papel dominante en la formación de las especies (Coyne \& Orr 2004), particularmente en la especiación rápida. Y, por cierto, no existe relación necesaria entre cambio morfológico y especiación.

2. Especiación y persistencia específica. El propio Mayr señaló tempranamente que la formación de dos o más especies a partir de una ancestral no es sino parte del proceso de diversificación. Las noveles especies deben también ser capaces de persistir para incrementar la diversidad biológica. En un influyente trabajo, Futuyma (1987) encontró allí una posible explicación de corte neodarwinista a la aparente asociación entre divergencia morfológica y persistencia. Según este autor, aunque no existe relación causal alguna entre cambio morfológico y especiación, la divergencia morfológica es siempre endeble si ocurre dentro de una especie, pero tiene más probabilidades de persistir si se asocia con conjuntos de individuos aislados reproductivamente (i.e., especies). Finalmente, la divergencia morfológica puede ser un componente de una divergencia de nichos entre especies, reduciendo la competencia y aumentando la probabilidad de persistencia. Gould (2002) acabó por aceptar esta explicación del fenómeno. 
3. Las causas de la estasis. Gould, Eldredge y otros plantearon que la causa de la estasis residía en restricciones evolutivas que solamente las peculiares circunstancias de la especiación peripátrida lograban quebrar. Existen dos grandes clases de restricciones de naturaleza marcadamente diferente. En primer lugar, las especies pueden carecer de la variación heredable necesaria para que la selección cambie los caracteres. En segundo lugar, la selección misma puede actuar contra cierta clase de cambios, por sus consecuencias deletéreas directas (el carácter sería menos adaptativo) o indirectas (existen correlaciones entre el carácter de interés y otros cuyo cambio sería menos adaptativo). En la actualidad existe consenso en el sentido de que la segunda clase de restricciones, que por cierto caen cómodamente dentro del marco explicativo del neodarwinismo, son las principales. De todos modos, la ausencia de oferta mutacional puede ser un importante factor limitante de la evolución en ciertos casos.

4. Selección clásica y selección de especies. El modelo de equilibrios puntuados motivó dos corolarios sobre la eficacia y niveles en que actúa la selección natural. Un primer punto de vista sugiere que la selección natural clásica opera dentro de las especies, y que los cambios no selectivos asociados a la especiación generan unidades de nivel superior (las especies) que pueden competir cuando tienen propiedades emergentes que afectan sus probabilidades de extinción y especiación. Un segundo punto de vista destaca la ineficacia de la selección clásica (a la vista del fenómeno de estasis) y propone que la mayor parte del cambio evolutivo resulta de la selección de especies. Elisabeth Vrba (1983) ha insistido en el primer punto de vista, y señalado que, para aceptar un caso de selección de especies, debe mostrarse que la selección ha operado sobre una propiedad emergente de esas entidades. Si las especies son más o menos exitosas como consecuencia de propiedades emergentes del nivel organísmico, entonces se trata de un efecto a nivel de especies de la selección clásica. Esta distinción restringe de manera muy importante la selección de especies, y abre un importante campo de interacción entre la selección clásica y los patrones macroevolutivos (por una visión menos restrictiva basada en "eficacia emergente" véase Gould 2002: 656-666). Por otra parte, un simple razonamiento poblacional sugiere que la selección de especies tenderá siempre a ser mucho menos eficaz que la clásica. Como sabemos, la unidad de tiempo para un proceso poblacional es la generación. Si la estasis es un fenómeno real y las especies no cambian por millones de años, el tiempo generacional es de millones de años para las especies. Además, el número de "individuos" será pequeño (el número de especies en cada momento). La eficacia de la selección depende de su intensidad relativa con respecto a las fluctuaciones por azar provocadas por la deriva, y éstas son función inversa del tamaño poblacional (Fisher 1930). La combinación de estos dos factores llevará a que la selección de especies no sea demasiado eficaz. En cambio, la selección clásica involucra muchos más individuos, por lo que puede ser eficaz con intensidades mucho más modestas, y opera a un ritmo mucho más rápido.

En resumen, el modelo de equilibrios puntuados ha destacado un fenómeno (la estasis) digno de atención, pero ha fracasado en su pretensión de relegar a la selección clásica a un segundo plano y asignar a la selección de especies un papel dominante en la evolución morfológica. En el camino, ha abierto las puertas a una visión jerárquica de la individualidad biológica. La insistencia del neodarwinismo clásico en el papel exclusivo de la selección operando sobre los organismos en las poblaciones, ha cedido terreno a la posibilidad de que otros tipos de entidades biológicas, como lo son el gen y la célula por debajo, y la especie por encima del nivel de los organismos multicelulares, puedan también involucrarse en procesos poblacionales en su propia escala, y no solamente "al servicio" de los organismos o como corolarios de su adaptación. La individualidad biológica representada, por ejemplo, por un organismo multicelular, es también fruto de la evolución, y es posible reconocer individualidad, y por tanto unidades potenciales de competencia y selección, a distintos niveles de la jerarquía biológica. Dicho esto, el neodarwinismo ha tenido éxito en su defensa del papel principal, aunque no necesariamente exclusivo, de la selección clásica a nivel de los organismos en la evolución.

Aun los organismos relativamente más simples, como algunas bacterias, contienen genomas, 
estructuras fenotípicas y capacidades fisiológicas de una gran complejidad, resultado de un largo proceso evolutivo. Muchas de esas propiedades son adaptativas y, por tanto, fruto de procesos de selección natural en su génesis y persistencia. Sin embargo, la maleabilidad de la vida y su capacidad de respuesta a las presiones selectivas tienen su contracara en el carácter condicional de la selección natural, que solamente opera en cada generación, como vimos, en base a la diversidad existente y su contexto. Es evidente, por tanto, que el estado de una población, la variación que contiene, y la complejidad estructural de los organismos que la integran, condicionan fuertemente la forma que puede tomar la selección y, más en general, el curso de la evolución futura de una especie. Es precisamente la inercia histórica de los linajes la que deja huella de la trama genealógica de la diversidad actual. Sin ella sería imposible reconstruir el árbol de la vida y, más en general, las secuencias de cambio en la evolución de un grupo cualquiera. El estudio de las restricciones (estructurales, de desarrollo, históricas) y su interacción con los fenómenos selectivos presenta importantes desafíos a la moderna teoría de la evolución, y ha motivado importantes ajustes en el marco de la teoría neodarwinista. Como en el caso del neutralismo, el análisis de las restricciones en la evolución encuentra su mayor riqueza en interacción con el estudio de la selección natural, más que en oposición al mismo.

\section{Otros Desarrollos}

En los últimos cincuenta años se han planteado, en adición a los enumerados anteriormente, numerosos problemas y desarrollos a la biología evolutiva. En ese contexto, he elegido destacar con fines ilustrativos los siguientes:

1. Pensar en base a árboles ("tree thinking"). Hemos visto que la descripción darwiniana de la evolución de las especies como un proceso de ramificación fue una innovación que se adoptó de manera definitiva. En los últimos años, ese germen darwiniano ha explotado, desde los trabajos pioneros de Hennig en sistemática filogenética hasta ocupar todos los rincones de la disciplina. Usamos árboles para entender la evolución de las especies, claro está, y el actual proyecto del árbol de la vida pretende realizar el sueño darwiniano. Pero también usamos árboles para entender la dinámica de la evolución viral, la evolución de familias multigénicas, la historia biogeográfica de la vida, la evolución de los rasgos de los organismos, etc. La teoría del coalescente de Kingman (1982), que representa el desarrollo más importante en genética de poblaciones después de la teoría neutral, se basa en las propiedades genealógicas de muestras de alelos.

2. Dinámica de evolución genómica. Los genomas enteramente secuenciados, que se acumulan a un ritmo creciente, presentan enormes desafíos y oportunidades para el estudio de la evolución. Es ya evidente que la dinámica de la evolución genómica es bastante más heterogénea de lo que se hubiese podido anticipar hace dos décadas. Traslocaciones, duplicaciones y deleciones de genes, transferencia de genes entre linajes divergentes, y muchos otros fenómenos contribuyen a la maleabilidad de los genomas. Nuevamente, azar, inercia histórica, y diversas formas de selección, emergen como conceptos poderosos para comenzar a entender la dinámica evolutiva a este nivel.

3. Evolución y desarrollo. En la década de 1980 fructificó la búsqueda de genes reguladores de los grandes patrones de desarrollo embrionario (genes Hox), primero en Drosophila, y luego en una gran diversidad de organismos. Una de las principales sorpresas fue el constatar que los mismos conjuntos de genes homólogos operan en la regulación del desarrollo de organismos muy divergentes, como insectos y vertebrados. Esta "homología profunda" de genes que subyacen a la regulación del desarrollo abrió importantes oportunidades para comprender la evolución de la diversidad y complejidad morfológicas. Como es natural, en este campo se aplica el "pensamiento en base a árboles", tanto para los genes como para los organismos, y más en general el pensamiento darwiniano sobre la diversificación biológica, con la ventaja de conocer el sustrato genético de dicha diversificación. Es también importante señalar que el desarrollo de este campo no provino exclusivamente del desarrollo de los análisis moleculares, sino de la confluencia de éstos con la observación de la diversidad morfológica y su manifestación en el desarrollo embrionario (véase Gilbert 2006: cap. 23). 
4. Procesos de especiación. Darwin se planteó dos problemas relacionados, como lo son la naturaleza de las especies y los procesos que llevan a su formación (especiación). Como se ha visto, el tema cobró relevancia con la obra de Mayr (1942), y no ha cesado de crecer en años recientes (Coyne \& Orr 2002). Casi se podrían trasladar aquí los comentarios realizados más arriba sobre la confluencia del naturalismo y la biología molecular en el estudio del nexo entre biología del desarrollo y evolución. En efecto, el campo de la especiación ha mantenido su raíz naturalista desde Mayr, adoptando nuevas herramientas de análisis (en particular, filogenéticas, genético-poblacionales y, más recientemente, genómicas). Entre las principales tendencias observamos las siguientes: a) un menor énfasis en el marco espacial (geográfico, semigeográfico, no geográfico); b) un mayor interés en la interrelación entre radiación filogenética y condiciones ecológicas (Schluter 2000); y c) esfuerzos específicos por develar las bases genéticas de la especiación (e.g., Carneiro et al. 2009; Kulathinal et al. 2009).

\section{LA EVOLUCIÓN HOY}

El ritmo de avance de la biología como disciplina ofrece innumerables problemas que requieren abordajes evolutivos. Como en el caso de los genes Hox, algunos problemas que ya estaban presentes en la época de Darwin pueden ser abordados con otras bases empíricas y metodológicas. En este contexto, es notable la vigencia y persistencia de los principales aportes de Darwin (nuevamente, procesos de diversificación en el árbol de la vida, azar y selección natural).

Por otra parte, resulta también significativo que la construcción de una visión moderna y amplia de la biología debiera reunir, y no confrontar, las mejores tradiciones del naturalismo, con su énfasis en la biodiversidad, y la tradición analítica de la genética, la bioquímica y otras disciplinas. La teoría sintética debió superar las barreras que existieron, en su momento, entre la genética y el naturalismo, y sus logros resultaron de la incorporación de puntos de vista inicialmente antagónicos en una visión integrada. En la actualidad, las tradiciones analíticas y el estudio de la diversidad biológica van de la mano, aunque no siempre en armonía, en la investigación de los genomas y su expresión en la estructura y funciones de los organismos, y el análisis de muy amplios sectores del árbol de la vida cuyo conocimiento es apenas rudimentario. Como es natural, nuestros mayores vacíos de conocimiento residen en el microcosmos de organismos unicelulares, menos pasibles de ser observados de manera directa. Sin embargo, la investigación de la diversidad de organismos multicelulares está también, aunque en menor medida, en sus albores, y nuestras mejores estimaciones sugieren que conocemos, aún en el sentido más elemental, una fracción relativamente pequeña de las especies que comprende.

\section{AGRADECIMIENTOS}

Agradezco a Guillermo D’Elía la invitación a contribuir con este ensayo. Algunos fragmentos fueron tomados de un ensayo solicitado por Bettina Tassino y Ana Celia Silva, a quienes agradezco también por su insistencia.

\section{BIBLIOGRAFÍA}

Carneiro, M., N. Ferrand, \& M.W. Nachman. 2009. Recombination and speciation: Loci near centromeres are more differentiated than loci near telomeres between subspecies of the European rabbit (Oryctolagus cuniculus). Genetics 181(2):593.606.

Cohen, I. B. 1985. Revolution in science. Belknap Press, Harvard University Press, Cambridge, Massachusetts.

Coyne, J.A. \& H.A. Orr. 2004. Speciation. Sinauer Associates Inc., Sunderland, Massachusetts.

DobZhansky, T. 1937. Genetics and the origin of species. Columbia University Press, New York.

ELDREDGe, N. \& S.J. Gould. 1972. Punctuated equilibrium: an alternative to phyletic gradualism. En: Models in paleobiology ( Ed. Shopf, T.J.M.), pp 82-115. Freeman, Cooper \& Co., San Francisco.

Fisher, R. A. 1930. The genetical theory of natural selection. Oxford University Press, Oxford.

Foster, P. L. 2000. Adaptive mutation: implications for evolution. BioEssays 22(12):1067-1074.

Futuyma, D. J. 1987. On the role of species in anagenesis. The American Naturalist 130(3):465-473.

Ghiselin, M. T. 1969. The triumph of the Darwinian method. University of California Press, Berkeley.

Gilbert, S. F. 2006. Developmental biology. $8^{\text {th }}$ Edition. Sinauer Associates, Inc, Sunderland, 
Massachusetts.

Gould, S. J. 2002. The structure of evolutionary theory. Belknap Press, Harvard University Press.

Kimura, M. \& T. OHta. 1971. Protein polymorphism as a phase of molecular evolution. Nature 229(5285):467-469.

Kingman, J. F. C. 1982. On the genealogy of large populations. Journal of Applied Probability 19A:27-43.

Kulathinal, R. J., L. S. Stevison, \& M. A. F. Noor. 2009. The genomics of speciation in Drosophila: diversity, divergence, and introgression estimated using low-coverage genome sequencing. PLOS Genetics 5(7):1-7.

Lessa, E. P. 1996. Darwin versus Lamarck. Cuadernos de Marcha, Tercera Época, Año 11, №. 116:58-64.

Lu, J. \& Wu, C.-I. 2005. Weak selection revealed by the whole genome comparison of the $\mathrm{X}$ chromosome and autosomes of human and chimpanzee. Proceedings of the National Academy of Sciences USA 102(11):40634067.

Lyell, C.1830. The principles of geology. Vol. 1. Murray, London.

MAYR, E. 1942. Systematics and the origin of species. Columbia University Press, New York.

MAYr, E. 1991. One long argument-Charles Darwin and the genesis of modern evolutionary thought. Harvard University Press, Cambridge, Massachusetts.

Онта, Т. 1973. Slightly deleterious mutant substitutions in evolution. Nature 246(5428):96-98.

Schluter, D. 2000. The ecology of adaptive radiation. Oxford University Press, Oxford.

VRBA, E. 1983. Macroevolutionary trends: new perspectives on the roles of adaptation and incidental effects. Science 221(4608):387-389. 